\title{
Activity of Selected Essential Oils against Candida spp. strains. Evaluation of New Aspects of their Specific Pharmacological Properties, with Special Reference to Lemon Balm
}

\author{
Aleksandra Budzyńska ${ }^{1}$, Beata Sadowska ${ }^{1}$, Grażyna Lipowczan ${ }^{2}$, \\ Agnieszka Maciąg ${ }^{3}$, Danuta Kalemba ${ }^{3}$, Barbara Różalska ${ }^{*}$ \\ ${ }^{1}$ Department of Immunology and Infectious Biology, University of Lodz, Poland \\ ${ }^{2}$ dr Wł. Biegański Provincial Specialist Hospital in Lodz, Diagnostic Laboratory, Poland \\ ${ }^{3}$ Institute of General Food Chemistry, Lodz University of Technology, Poland \\ Email: *rozab@biol.uni.lodz.pl
}

Received June 5, 2013; revised July 5, 2013; accepted July 15, 2013

Copyright (C) 2013 Aleksandra Budzyńska et al. This is an open access article distributed under the Creative Commons Attribution License, which permits unrestricted use, distribution, and reproduction in any medium, provided the original work is properly cited.

\begin{abstract}
The aim was to investigate the antifungal effectiveness and some of pharmacological properties of essential oils (EOs), which had not yet been thoroughly studied in the planned scope. We first evaluated MIC/MFC of sixteen EOs against $C$. albicans ATCC 10231. Then, five most active EOs were tested, using 50 clinical Candida spp. strains and additional reference $C$. albicans ATCC 90028 strain. The time-kill curve, carryover, post-antifungal effects (PAFE), mutant prevention concentrations, the susceptibility of reference strains to the cell wall disrupting agents and tolerance to oxidative stress, were evaluated. For these detailed studies, we chose the following four essential oils. Clove oil, Geranium oil, Lemon balm and Citronella oil, with MICs of $0.097 \%(\mathrm{v} / \mathrm{v})$, resulted concentration- and time-dependent killing and may be therapeutically safe, because they do not generate resistance. The best one was Lemon balm, which caused most extended PAFE, significantly reduced tolerance to oxidative stress and increased susceptibility to Calcofluor White, Congo Red and SDS. Phytochemical analysis of these four EOs has been performed and compared; looking for the reason that Lemon balm was the best.
\end{abstract}

Keywords: Candida; Cell Wall Sensitivity; Essential Oils PAFE; Mutant Generation; Oxidative Stress Tolerance; Time-Killing

\section{Introduction}

Numerous members of Candida spp. are commensal organisms colonizing several ecological niches of healthy individuals. On the other hand, they are also the most frequent pathogens in humans at risk. Depending on the immunological state of the host, candidiasis can develop as mild superficial infection or very dangerous, life threatening invasive one. Epidemiological data also show an increase in local fungal infections of chronic wounds (diabetic foot, burn, bed-sore, cancer ulceration), with the participation of C. albicans biofilm. Such infections, similarly to systemic ones, are very difficult to eradicate since Candida cells living as a biofilm community show extremely high resistance to most of the currently used

"Corresponding author. antifungal drugs $[1,2]$. Despite the discovery in the last decades of potent antimycotics, most types of systemic and local Candida infections still remain a serious medical problem. Thus, it is pivotal to discuss various strategies that may become therapeutic tools in future, in which the search for agents with novel mechanisms of action should be considered. The most intensively studied option is using plant products as factors modulating the resistance of microorganisms [3]. Indeed, many compounds of plant origin affect some structures and some of the mechanisms responsible for the resistance phenotype in bacteria and fungi. A very interesting trend of worldwide studies is the possible synergism that may occur between, for example, plant-derived agents and antibiotics or other chemotherapeutics. It can result in strong growth inhibition even of drug-resistant microbes (bacte- 
ria or fungi) and the ability to obtain a stronger post-antibiotic effect [4-9]. Generally, studies on the possible use of plant-derived compounds for combating human pathogens are being carried out worldwide and knowledge coming from in vitro studies in this field is already quite extensive. However, the modern approach to observations drawn from folk medicine is to clarify the mechanisms of their activity, forming the basis for safe use. The main objective of the present study was to investigate the possibility of using essential oils as potential medicinal substances active against Candida spp. For this purpose, the essential oils were chosen which had not yet been thoroughly studied in the planned scope. As target microorganisms we used C. albicans reference strains and a group of $C$. albicans and various non-albicans Candida clinical isolates. More detailed research, concerning time-kill curve, carryover and post-antifungal effects as well as the mutant prevention concentration of four selected the most active essential oils, was conducted. Also, the susceptibility of $C$. albicans to cell wall disrupting agents and yeast cell tolerance to oxidative stress induced by hydrogen peroxide, after treatment with essential oils were estimated. For these preparations the phytochemical analysis has also been performed.

\section{Materials and Methods}

\subsection{Candida Strains and Culture Conditions}

A total of 52 strains were tested for their susceptibility to essential oils. These comprised two reference C. albicans strains (ATCC 10231, ATCC 90028) and 50 clinical isolates: C. albicans $(\mathrm{n}=20)$, C. glabrata $(\mathrm{n}=13), C$. krusei $(\mathrm{n}=6)$, C. parapsilosis $(\mathrm{n}=5)$, C. tropicalis $(\mathrm{n}=6)$. The Candida isolates were obtained from cultures of blood, wounds swabs, stool and various mucosal tissue specimens of patients hospitalized at Dr Wł. Biegański Provincial Specialist Hospital in Lodz, Poland. Suspensions of the yeasts for each test were prepared from fresh (24 h-old) cultures grown at $35^{\circ} \mathrm{C}$ on Sabouraud Dextrose agar (SDA, Difco Laboratories, USA) or if necessary on YPG P-0035 medium (Yeast Extract Peptone Glucose, BTL, Poland).

\subsection{Essential oils, MIC and MFC Determination}

Essential oils (EOs) of plants listed in Table 1. were used, all purchased from Pollena Aroma, Poland. The initial screening of 16 EOs activity was performed by broth microdilution method, according to the guidelines of EUCAST with minor modifications [10,11], using C. albicans ATCC 10231 strain as a target organism. Then, the MIC/MFC (minimum inhibitory/fungicidal concentration) of 5 most active EOs against 50 clinical Candida spp. and additional reference (C. albicans ATCC 90028) strains was evaluated, using the same experimental pro-
Table 1. List of essentials oils tested at different stages of research.

\begin{tabular}{|c|c|c|c|c|}
\hline Plant species & Essential Oil & 1 & 2 & 3 \\
\hline Lavandula angustifolia & Lavender oil & & $\bullet$ & \\
\hline Melaleuca alternifolia & Tea tree oil & $\bullet$ & & \\
\hline Citrus limon & Lemon oil & $\bullet$ & & \\
\hline Anthemis nobilis & Anthemis oil & $\bullet$ & & \\
\hline Melissa citrata indica & Lemon balm & & & $\bullet$ \\
\hline Pinus sylvestris & Scott pine & $\bullet$ & & \\
\hline Ribes nigrum & Black currant & $\bullet$ & & \\
\hline Cymbopogon citratus & Citronella oil & $\bullet$ & & $\bullet$ \\
\hline Pimpinella anisum & Oleum anisi & $\bullet$ & & \\
\hline $\begin{array}{l}\text { Pelargonium } \\
\text { graveolens }\end{array}$ & Geranium oil & & & $\bullet$ \\
\hline Eugenia caryophyllata & Oleum Caryophylli (Clove oil) & $\bullet$ & & $\bullet$ \\
\hline Hyssopus officinalis & Hyssop oil & $\bullet$ & & \\
\hline Mentha piperita & Peppermint oil & $\bullet$ & & \\
\hline Thymus vulgaris & Thyme oil & $\bullet$ & & \\
\hline Rosmarinus officinalis & Rosemary oil & $\bullet$ & & \\
\hline Abies sibirica & Abies oil & • & & \\
\hline
\end{tabular}

1-MIC/MFC evaluation; C. albicans ATCC 10231, 2-MIC/MFC evaluation; 50 clinical Candida spp. strains, C. albicans ATCC 90028, 3-tests evaluating selected pharmacological properties; C. albicans ATCC 10231, C. albicans ATCC 90028.

tocol. Briefly, EOs (concentrations at range $6.25 \%$ $0.024 \%, \mathrm{v} / \mathrm{v})$ were deposited $(100 \mu \mathrm{L})$ in triplicate in the wells of flat-bottom polystyrene 96-well microplates (Nunc, Denmark). Then, $100 \mu \mathrm{L}$ of yeast suspension $\left(10^{5}\right.$ CFU/mL in RPMI-1640/0.5\% Tween 20) was added. The positive control was a suspension of yeasts in the culture medium, and the negative control was the medium. After $48 \mathrm{~h}$ incubation at $35^{\circ} \mathrm{C}$, the absorbance at $\mathrm{A}_{600}$ (multicounter Victor 2, Wallac, Finland) was determined. The endpoint was defined as the lowest concentration of the compound resulting in total inhibition $\left(\mathrm{MIC}_{100}\right)$ of yeast growth, compared to the growth in the control wells. The lowest concentration of essential oils fungicidal to $\geq 99.9 \%$ of the original inoculum (MFC) was determined paralelly, by subculturing $10 \mu \mathrm{L}$ from the wells with suspected MIC, 2x, 4x MIC, on the SDA without any antimicrobial agents. No visible colony growth after subsequent $24-48 \mathrm{~h}$ incubation was accepted as MFC. All experiments were conducted in duplicate.

\subsection{GC-FID-MS Analysis of Selected EOs}

Essential oils were analyzed using Trace GC Ultra (Thermo Electron Corporation) equipment combined with 
DSQ II mass spectrometer and with flame ionization detector (FID) throughout MS-FID Splitter. Analysis was provided using nonpolar chromatography column: Rtx-1 $\mathrm{ms}$ (Restek) $60 \mathrm{~m}$ length, inner diameter $0.25 \mathrm{~mm}$, film thickness $0.25 \mu \mathrm{m}$. Temperature programme: $50^{\circ} \mathrm{C}(3$ min), temperature rise $4^{\circ} \mathrm{C} / \mathrm{min} ; 310^{\circ} \mathrm{C}(10 \mathrm{~min})$; injector temperature $280^{\circ} \mathrm{C}$; detector temperature $310^{\circ} \mathrm{C}$. Hellium was used as a carrier gas which was pressurized to 300 $\mathrm{kPa}$, ionization energy $70 \mathrm{eV}$, ion source temperature $200^{\circ} \mathrm{C}$. Identification of components was based on the comparison of their MS spectra with those in a laboratory-made MS library, commercial libraries (NIST 98.1 and Mass Finder 4) along with the retention indices associated with a series of alkanes with linear interpolation (C8-C26). A quantitative analysis (expressed as percentages of each component) was carried out by peak area normalization measurements without correction factors.

\subsection{EOs Killing Kinetics Assay}

In time-kill curve studies, four most active essential oils were used against C. albicans ATCC 10231 and C. albicans ATCC 90028 strains. These are EOs obtained from the following plants: Cymbopogon citratus (Citronella oil), Pelargonium graveolens (Geranium oil), Eugenia caryophyllata (Clove oil), Melissa citrata indica (Lemon balm). The inoculum suspension $\left(5 \times 10^{5} \mathrm{CFU} / \mathrm{mL}\right)$ was prepared in $10 \mathrm{~mL}$ of RPMI-1640 (Cytogen, Poland) with or without EOs in the concentrations range from $1 / 2$ MIC to $2 x$ MICs. At predetermined time points $(0,0.5,1$, $2,4,6,8,24$ and $48 \mathrm{~h}$ ) of incubation at $35^{\circ} \mathrm{C}$, a $100 \mu \mathrm{L}$ samples were serially diluted in sterile water. Then, each $100 \mu \mathrm{L}$ aliquot was plated onto SDA plates for CFU counting, after $24-48 \mathrm{~h}$ incubation at $35^{\circ} \mathrm{C}$. The results were reported as the mean percentage of survival \pm standard deviation of four replicates, conducted for each compound twice.

\subsection{EOs Carryover Effect}

Fungal suspensions (C. albicans ATCC 10231 and $C$. albicans ATCC 90028) of approximately $5 \times 10^{3} \mathrm{CFU} /$ $\mathrm{mL}$ were prepared in RPMI-1640 medium, and $100 \mu \mathrm{L}$ of each was added to $900 \mu \mathrm{L}$ of sterile water without or with EO (at MIC to $4 x$ MIC). Immediately after the addition of the fungal suspension to the agent solution, the test tubes were vortexed and $50 \mu \mathrm{L}$ aliquots were plated on the SDA. Following $48 \mathrm{~h}$ of incubation at $35^{\circ} \mathrm{C}$, the CFU of Candida was determined. The mean colony count at each multiple of the MIC tested was compared with the data for the control. A significant antifungal carryover was defined as $>25 \%$ reduction in CFU in comparison to the control level. The experiments were conducted in duplicate.

\subsection{Post-Antifungal Effect (PAFE) of EOs}

The PAFE of EOs against C. albicans ATCC 10231 and C. albicans ATCC 90028 strains was estimated. The inoculum suspensions $\left(5 \times 10^{5} \mathrm{CFU} / \mathrm{mL}\right)$ were prepared in $10 \mathrm{~mL}$ of RPMI-1640 with or without EO (at MIC and 2x MIC). After $1 \mathrm{~h}$ exposure to the EOs, samples were diluted 1:100 in pre-warmed medium to effectively remove the EOs. The diluted cultures were then incubated with agitation $(200 \mathrm{rpm})$ at $35^{\circ} \mathrm{C}$. At the desired time points, $100 \mu \mathrm{L}$ from each sample was serially diluted 10 -fold in sterile water, and $100 \mu \mathrm{L}$ was plated on SDA. Following incubation at $35^{\circ} \mathrm{C}$ for $48 \mathrm{~h}$, the number of CFU was counted. The PAFE was calculated using the formula: $\mathrm{PAFE}=\mathrm{T}-\mathrm{C}$, where $\mathrm{T}$ represents the time required for the CFU to increase $1 \log _{10} \mathrm{CFU} / \mathrm{mL}$ in the test culture above the CFU observed immediately after $\mathrm{EO}$ removal, and $\mathrm{C}$ represents the time required for the count of the untreated control tube to increase by $1 \log _{10}$ $\mathrm{CFU} / \mathrm{mL}$. The experiments were performed in duplicate.

\subsection{Selection of Single-Step EOs-Resistant Mutants}

In order to evaluate the frequency of spontaneous singlestep mutations of C. albicans ATCC 10231 and C. albicans ATCC 90028 strains, a fungal suspension containing $\sim 10^{10} \mathrm{CFU}$ was plated on SDA plates $(24 \mathrm{~cm}$ in diameter) containing each $\mathrm{EO}$ at concentrations from 1 to $8 \mathrm{x}$ MIC. Mutation frequency was expressed as a number of resistant colonies per inoculum. It was calculated by counting the total number of colonies appearing after 7 days of incubation at $35^{\circ} \mathrm{C}$ on a plate containing EOs and by dividing this number by the total number of CFU plated. The experiment was repeated twice with three plates for each EO concentration.

\subsection{Candida Susceptibility to Cell Wall Disrupting Agents and Oxidative Stress Tolerance under the Influence of Essential Oils}

Fresh suspensions of C. albicans ATCC 10231 and $C$. albicans ATCC 90028 in RPMI-1640 medium, prepared from cultures on SDA, were exposed to EOs at MIC for $1 \mathrm{~h}, 35^{\circ} \mathrm{C}$. Other set of suspensions were prepared after yeasts culture $\left(24 \mathrm{~h}, 35^{\circ} \mathrm{C}\right)$ in the presence of $1 / 2 \mathrm{MIC}$ oils (agar dilution). Control suspensions were left without EOs influence. Examination of Candida samples exposed to EOs at MIC, was preceded by washing three times in order to avoid carryover effect. The volume of 5 $\mu \mathrm{L}$ of ready-to-use suspensions with densities of $10^{5}, 10^{4}$, $10^{3}$ cells $/ \mathrm{mL}$ were spotted on YPG plates containing one of the following cell surface disrupting agents: Calcofluor White $(5 \mu \mathrm{g} / \mathrm{mL}, 10 \mu \mathrm{g} / \mathrm{mL})$, sodium dodecyl sulfate (SDS) $(0.02 \%, 0.03 \%, 0.05 \%)$ and Congo Red 
$(20 \mu \mathrm{g} / \mathrm{mL}, 50 \mu \mathrm{g} / \mathrm{mL})$; all agents were purchased from Sigma, USA; the above concentrations were chosen after preliminary studies. The plates were incubated at $30^{\circ} \mathrm{C}$ and monitored for Candida growth during 3 days. Each of the experiments was performed in triplicate. To test the oxidative stress tolerance, the remainder of Candida cell suspensions $\left(10^{5}\right)$, pre-exposed to essential oils or control suspensions, were transferred to Eppendorf tubes in a volume of $1 \mathrm{~mL}$ and treated with hydrogen peroxide $(12.5,25$ or $50 \mathrm{mM})$ for $1 \mathrm{~h}$ at $35^{\circ} \mathrm{C}$. Then, fungal suspensions were diluted $\left(10^{5}\right.$ to $10^{3}$ cells $\left./ \mathrm{mL}\right)$ and spotted $(5 \mu \mathrm{L})$ onto YPG plates. Their growth was monitored for 3 days and compared to the growth of control cultures not treated with EOs and untreated with hydrogen peroxide.

\subsection{Statistical Analysis}

If necessary, differences in parameters were tested for significance using "U" Mann-Whitney test and computer program Statistica 5.0.

\section{Results}

Screening of sixteen essential oils (EOs), listed in Table 1, against reference $C$. albicans ATCC 10231 strain has confirmed their known, usually high fungistatic/fungicidal activity. Of the preparations used, five EOs which were most active, and not so well-known when it comes to the scope of our research (Lavender oil, Lemon balm, Citronella oil, Geranium oil, Clove oil), were classified to the second step. In the further experiments, the clinical isolates representing C. albicans $(\mathrm{n}=20), C$. glabrata $(\mathrm{n}$ =13), C. krusei $(\mathrm{n}=6), C$. parapsilosis $(\mathrm{n}=5)$, C. tropicalis $(\mathrm{n}=6)$ species and additional reference strain $-C$. albicans ATCC 90028, have been tested as targets. Similar ranges of MIC $(0.024 \%-0.39 \%, \mathrm{v} / \mathrm{v})$ for $C$. albicans, and non-albicans clinical strains were noted. However, the fungicidal activity of tested EOs differed, with respect to $C$. albicans and other species. The minimum fungicidal concentrations (MFCs) for C. glabrata, C. krusei, and C. parapsilosis individual strains varied but usually the concentration ranges were higher than that these active for C. albicans (Table 2). Then, the time kill curve, carryover, post-antifungal effect, mutant prevention concentrations, the susceptibility of Candida reference strains to the cell wall disrupting agents and yeast tolerance to oxidative stress, were evaluated. Clove oil, Geranium oil, Lemon balm and Citronella oil were used for these tests. The results of the experiments on killing kinetics of Lemon balm are shown in Figure 1. The fungicidal endpoint (99.9\% CFU reduction) for $C$. albicans ATCC 90028 was achieved after $4 \mathrm{~h}$ at MIC and after $1 \mathrm{~h}$ at 2x MIC, while for C. albicans ATCC 10231, respectively, after 6 and 2 h. Similar kinetics of killing was showed by Citronella oil.

Clove oil and Geranium oil revealed a 99.9\% fungicidal activity after a longer time (data not shown). Individual essential oils showed a concentration-dependent PAFE, which means inhibiting the re-multiplication of Candida. A 1-hour exposure to Lemon balm at MIC resulted in a long PAFE against both strains tested $(3 \mathrm{~h})$. This essential oil, when used at 2x MIC, caused PAFE which lasted $10 \mathrm{~h}$ against C. albicans ATCC 10231 and 5 h against $C$. albicans ATCC 90028. Citronella oil caused similarly strong PAFE, effectively inhibiting regrowth of C. albicans ATCC 10231 after $1 \mathrm{~h}$ at MIC and after $4 \mathrm{~h}$ at 2x MIC. The PAFE against C. albicans ATCC 90028 lasted even longer $-5 \mathrm{~h}$ at MIC and $7 \mathrm{~h}$ at $2 \mathrm{x}$ MIC. The PAFE of Geranium oil and Clove oil, both used at MIC, was weaker $(1 \mathrm{~h}$ and $3 \mathrm{~h}$, against $C$. albicans ATCC 10231 and C. albicans ATCC 90028, respectively). These two EOs, when used at $2 \mathrm{x}$ MIC, caused PAFE which was comparable strong with that of the above described Lemon balm and Citronella oil.

Due to the specific physical and chemical properties of essential oils, such as low density and oiliness, investiga-

Table 2. Fungicidal activity (minimal fungicidal concentrations, MFCs—\% v/v) of selected essentials oils: $1-$ Lavender oil, 2-Lemon balm, 3-Citronella oil, 4-Geranium oil, oil, 5-Clove oil.

\begin{tabular}{|c|c|c|c|c|c|}
\hline \multirow{2}{*}{ Candida strains } & \multicolumn{5}{|c|}{ MFC range $(\% \mathrm{v} / \mathrm{v})$} \\
\hline & 1 & 2 & 3 & 4 & 5 \\
\hline C. albicans ATCC 10231 & 0.19 & 0.097 & 0.097 & 0.19 & 0.19 \\
\hline C. albicans ATCC 90028 & 0.19 & 0.097 & 0.097 & 0.19 & 0.19 \\
\hline C. albicans clin., $\mathrm{n}=20$ & $0.097-0.78$ & $0.048-0.19$ & $0.048-0.39$ & $0.048-0.39$ & $0.048-0.78$ \\
\hline C. glabrata clin., $\mathrm{n}=13$ & $0.048-1.56$ & $0.12-1.56$ & $0.024-1.56$ & $0.024-0.78$ & $0.048-1.56$ \\
\hline C. krusei clin., $\mathrm{n}=6$ & $0.39-1.56$ & $0.78-1.56$ & $0.048-1.56$ & $0.019-0.78$ & $0.39-1.56$ \\
\hline C. parapsilosis clin., $\mathrm{n}=5$ & $0.048-1.56$ & $0.048-0.78$ & $0.048-1.56$ & $0.097-1.56$ & $0.097-1.56$ \\
\hline C. tropicalis clin., $\mathrm{n}=6$ & $0.024-0.19$ & $0.048-0.097$ & $0.097-0.19$ & $0.048-0.097$ & $0.097-0.39$ \\
\hline
\end{tabular}




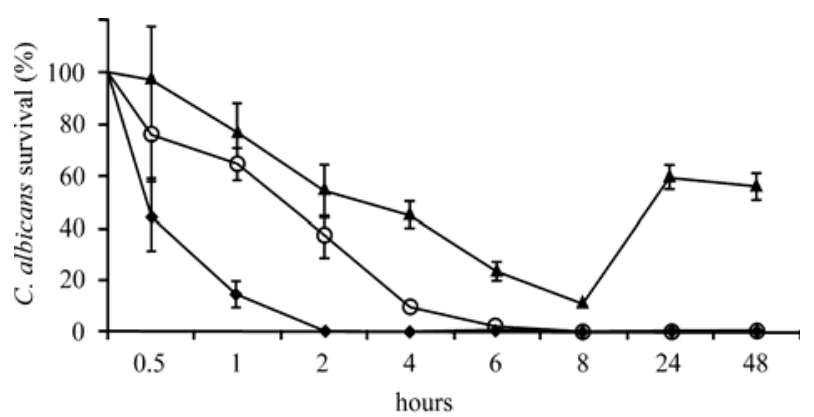

(a)

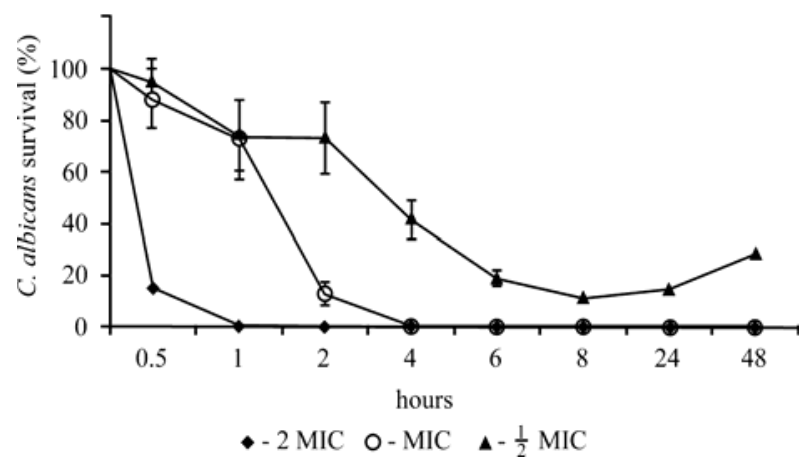

(b)

Figure 1. Time- and concentration-dependent effect of Lemon balm on C. albicans ATCC 10231. (a) or C. albicans ATCC 90028; (b) growth. The presented results are mean (\% of yeast survival $\pm S$. D.) from two independent experiments performed in quadruplicate, according to protocol described in detail in the Material and Methods section.

tion of carryover effect was included in our study. It was evaluated over a range of essential oils concentrations from $1 \mathrm{x}$ to $8 \mathrm{x}$ MIC. A significant antifungal carryover defined as $>25 \%$ reduction in CFU $/ \mathrm{ml}$ compared to the control value was showed for all essential oils tested, however, with a different multiple of the MIC. For Citronella oil and Geranium oil this effect was visualized at a concentration of $4-8 \mathrm{x}$ MIC, depending on the strain of Candida. However, carryover effect of Clove oil and Lemon balm was found at a concentration of $2 \mathrm{x}$ MIC. To eliminate the carryover effect of EOs in "PAFE experiments" described above, intensive rinsing of fungal cells, after their short-term exposure to oils was performed. The selection of one-step resistant mutants of $C$. albicans ATCC 10231 and C. albicans ATCC 90028 was performed with increased concentrations of each essential oil. Using the inocula total of $\sim 10^{10}$ Candida CFU, none of the tested EOs was shown as a selector of mutants at $2 \mathrm{x}$ to $8 \mathrm{x}$ MIC concentration. The mutation frequency for fungal cultures grown with MIC of EOs was $6.7 \times 10^{-9}$ only in the case of using Clove oil and Geranium oil against $C$. albicans ATCC 10231. However, these single colonies subcultured on media containing the same concentration of the essential oil did not grow back during further 7 days of incubation.

C. albicans cells when exposed to essential oils exhibited lower oxidative stress tolerance after treatment with various doses of hydrogen peroxide $(12.5,25$ and $50 \mathrm{mM})$ in comparison to the control cells. This effect was stronger in the case of C. albicans ATCC 90028 strain than ATCC 10231, regardless whether we used shortterm exposure $(1 \mathrm{~h})$ to oils at MIC or long-term exposure $(24 \mathrm{~h})$ at half MIC. Among the studied oils the most significant increase in susceptibility to hydrogen peroxide was caused again by Lemon balm (Figure 2). Spot plating of yeasts (previously treated with essential oils) on media containing different concentrations of various cell wall damaging agents resulted in delays and growth reduction. Representative results documenting the increased sensitivity of $C$. albicans ATCC 10231 and ATCC 90028 strains to selected concentrations of Calcofluor White, Congo Red and SDS are shown in Figure 3. They concern the effect caused by the Lemon balm.

The phytochemical analysis of four EOs, tested in details as described above, has been performed by GC-mass spectrometry. A quantitative analysis has been carried out by peak area normalization measurements without correction factors and presented in Table 3, as percentages of each component. Lemon balm contained higher percentage of monoterpene hydrocarbons $(10.9 \%)$ than Citronella oil $(3.5 \%)$. The other two oils-Geranium oil and Clove oil do not contain such ingredients. On the other hand, only Clove oil contain phenylpropane fraction, which accounted for $86 \%$ of the total compounds. Quantitative analysis and comparison of the composition of the four EOs showed significant differences in the individual components which are the most well-known

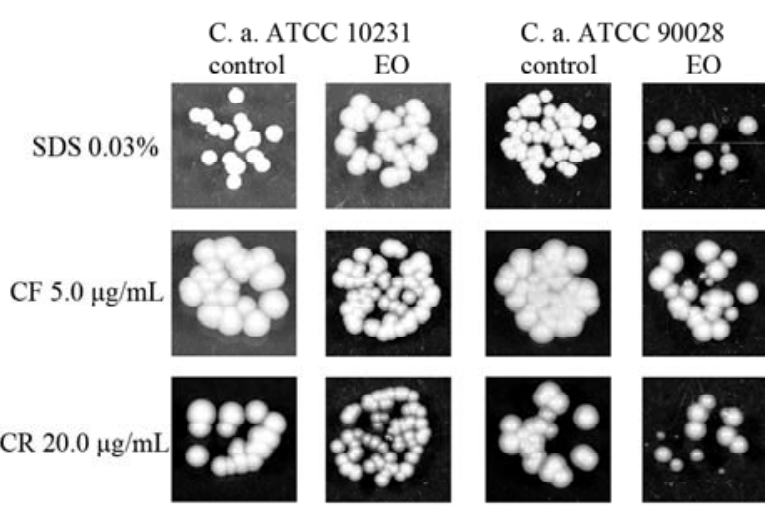

Figure 2. Susceptibility of C. albicans ATCC 10231 or $C$. albicans ATCC 90028 to cell wall disrupting agents. First panel-growth on $0.03 \%$ SDS containing medium; second panel-growth on Calcofluor White $5 \mu \mathrm{g} / \mathrm{mL}$ containing medium; third panel-growth on $20 \mu \mathrm{g} / \mathrm{mL}$ Congo Red containing medium. Strains were treated with Lemon balm (at MIC, $\left.1 \mathrm{~h}, 35^{\circ} \mathrm{C}\right)$, then diluted $\left(10^{5}\right.$ to $10^{3}$ cells $\left./ \mathrm{mL}\right)$, and spotted on YPG plates containing the cell surface disrupting agents. 

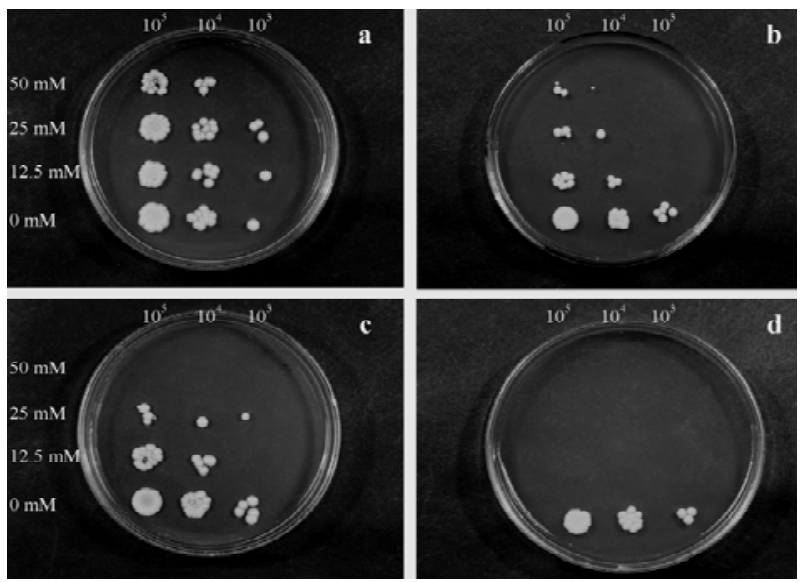

Figure 3. Oxidative stress assay. (a) C. albicans ATCC 10231, (c) C. albicans ATCC 90028) control plates (yeasts non-treated with Lemon balm); (b) C. albicans ATCC 10231, (d) C. albicans ATCC 90028 test plates (yeasts treated with MIC of EO, $1 \mathrm{~h}, 35^{\circ} \mathrm{C}$ ). Then, strains were incubated with different doses of hydrogen peroxide $(12.5-50 \mathrm{mM})$ for $1 \mathrm{~h}$, diluted $\left(10^{5}\right.$ to $10^{3}$ cells/ml) and spotted on YPG plates $(5$ $\mu L)$. Yeast cultures, untreated with $\mathrm{H}_{2} \mathrm{O}_{2}$, were spotted as controls.

for its antimicrobial activity. The highest concentration found in different oils was, as follows: eugenol (Clove oil, 86.2\%), citronellol (Geranium oil, 44.0\%); geraniol and citronellal (Citronella oil, 22.4\% and 36.2\%, respectively) and citral (neral + geranial) (Lemon balm, 8.6\% + $10.1 \%$ ).

\section{Discussion}

In our view, the most interesting field of world-wide study of plant-derived products is new applications of essential oils (EOs), such as alternative natural anti-fungal substances in some kinds of therapy, for example, topical administration. While the exact mechanism of most of them is still unclear, these herbal products have been widely explored in folk and traditional medicines and as an alternative to conventional chemotherapy. We consider the possibility of using them in the treatment of difficult to heal cancer ulceration, diabetic foot ulcers complicated by fungal, bacterial or mixed-etiology infections. Due to known toxic activity of EOs, their potential usage limited to the topical therapy is reasonable [2, 12-15]. Therefore, the main objective of the present study was firstly to investigate the antifungal effectiveness of EOs (listed in Table 1) and secondly, to establish some not described pharmacological properties, determining the impact of the most active among them, on the physiology of the yeasts. The obtained results indicate that essential oils chosen by us (Lavender oil, Clove oil, Geranium oil, Lemon balm and Citronella oil) showed a similar range of $\mathrm{MIC}$ but not $\mathrm{MFC}$ against $C$. albicans and non-albicans clinical strains, i.e. C. krusei, C. gla-
Table 3. Composition of selected essential oils: 1-Citronella oil, 2-Lemon balm, 3-Geranium oil, 4-Clove oil. RI-retention index, —not identified.

\begin{tabular}{|c|c|c|c|c|c|}
\hline \multirow{2}{*}{ Compound } & \multirow{2}{*}{$\mathrm{RI}_{l i t}$} & 1 & 2 & 3 & 4 \\
\hline & & \multicolumn{4}{|c|}{$[\%]$} \\
\hline$\alpha$-Pinene & 934 & - & 0.6 & 0.6 & - \\
\hline$\beta$-Pinene & 974 & - & 3.2 & - & - \\
\hline Limonene & 1025 & 3.5 & 6.6 & - & - \\
\hline Linalool & 1087 & 0.7 & - & 5.5 & - \\
\hline Citronellal & 1135 & 36.2 & 6.2 & - & - \\
\hline iso-Menthone & 1146 & - & - & 7.5 & - \\
\hline Citronellol & 1210 & 14.1 & 37.0 & 44.0 & - \\
\hline Neral & 1218 & 0.2 & 8.6 & - & - \\
\hline Geraniol & 1238 & 22.4 & 10.2 & 10.5 & - \\
\hline Geranial & 1247 & 0.2 & 10.1 & 0.4 & - \\
\hline Citronellyl formate & 1260 & - & 0.8 & 9.8 & - \\
\hline Geranyl formate & 1284 & - & - & 2.2 & - \\
\hline Eugenol & 1333 & - & - & - & 86.2 \\
\hline Citronellyl acetate & 1335 & 3.2 & $\mathrm{t}$ & 0.1 & - \\
\hline Geranyl acetate & 1363 & 2.8 & 0.1 & $\mathrm{t}$ & - \\
\hline$\beta$-Elemene & 1390 & 2.7 & 0.2 & - & - \\
\hline$(E)-\beta$-Caryophyllene & 1421 & 0.2 & 2.2 & 0.9 & 10.4 \\
\hline Elemol & 1540 & 3.3 & - & - & - \\
\hline Caryophyllene oxide & 1572 & - & 7.4 & 0.9 & 0.7 \\
\hline$\gamma$-epi-Eudesmol & 1618 & - & - & 4.2 & - \\
\hline \multicolumn{2}{|c|}{ monoterpene hydrocarbons } & 3.5 & 10.9 & - & - \\
\hline \multicolumn{2}{|c|}{ oxygenated monoterpenes } & 81.0 & 74.2 & 86.3 & - \\
\hline \multicolumn{2}{|c|}{ sesquiterpene hydrocarbons } & 8.8 & 5.5 & 3.6 & 12.7 \\
\hline \multicolumn{2}{|c|}{ oxygenated sesquiterpenes } & 5.5 & 8.1 & 6.2 & 0.7 \\
\hline \multicolumn{2}{|l|}{ phenylpropanes } & - & - & - & 86.2 \\
\hline
\end{tabular}

brata C. tropicalis and C. parapsilosis (Table 2).

Unfortunately, it coincides with the increasing resistance of these non-albicans species to antifungal drugs. The international surveillance of epidemiology and antifungal resistance of Candida spp. by SENTRY Antimicrobial Surveillance Program has found that the emergence of opportunistic pathogenic Candida spp. was continuously increasing in the order of C. albicans $(48.7 \%)$ non-albicans Candida, viz., C. parapsilosis $(17.3 \%), C$. glabrata (17.2\%), C. tropicalis (10.9\%), C. krusei (1.9\%) and other Candida spp. (4.0\%) [1]. 
Several of the 16 oils tested by us, which were further thoroughly examined (Clove oil, Geranium oil, Lemon balm and Citronella oil), showed strong effect on the cell wall and membrane of $C$. albicans. Furthermore, they caused long-lasting PAF effect and were shown as safe, because they did not generate resistance in one-step assay. Time-kill experiments revealed that all these EOs were fungicidal and acted quickly (starting from $0.5 \mathrm{~h}$ of co-incubation). The most effective was essential oil of Melissa citrata indica herb (Lemon balm), which caused the quickest decrease in cell density of $C$. albicans ATCC 90028 and less evident effect towards $C$. albicans ATCC 10231. What is more interestingly, a 1-hour exposure of $C$. albicans ATCC 90028 to Lemon balm resulted in the longest PAFE. To our knowledge, this report is the first one describing such effects of essential oils. Furthermore, MPC (mutant prevention concentration) of this oil, tested by single-step methodology was equal to or twice as high as their MICs, thus MSW (mutant selection window) was narrow [16-18].

One can ask a question what is so special in the physicochemical properties of Melissa essential oil that it exhibits such high activity against Candida. Until recently it was known that extracts and essential oils of Melissa sp. are used rather in traditional medicine to treat insomnia, anxiety, gastric conditions, psychiatric conditions, migraines, hypertension and bronchial conditions. Their antimicrobial/antiviral activity, although described, is definitely less known and no specific characterization has been provided, especially concerning anti-Candida activity. What was reported earlier the most important identified compounds of Lemon balm showing antimicrobial effects were geraniol, citral, citronellal, and transcaryophyllene which are also present in the composition of other essential oils with proven antimicrobial activity [19-21]. Since different chemotypes of the same species may grow in the same place, both the composition and antimicrobial activity may differ, even in the case of commercial essential oils. Therefore, it is important that the composition of the essential oil tested has to be given each time [22]. The main components of Melissa citrata indica essential oils tested in this study were identified by GC-mass spectrometer analyses. The percentage compositions is listed in Table 3. Indeed, citral (neral and geranial) was the main component of Lemon balm and according to many authors these aldehydes show high antimicrobial activity [13,19,22-24]. It is possible, however, that these and other compounds quantity/quality composition is relevant to Lemon balm highest anti-Candidal activity. It is known that the efficacy of the whole herb extract/oil may lie on the low doses of the active constituents present in an herbal product altogether. Quantitative analysis and comparison of the composition of the four EOs tested in the present report showed sig- nificant differences in the individual components which are the most well-known for its antimicrobial activity i.e. eugenol, citronellol, geraniol, citronellal, and citral (neral + geranial). Although oil of Melissa showed the most desirable properties, the other oils are also worthy of consideration as a potentially useful.

The results of our study concerning the action of Lemon balm and three other selected EOs clearly indicate, that the phenotypic features of Candida yeasts that decide about their success as invasive pathogens, were targets for their activity. The fungal cell wall is composed primarily of polysaccharides such as glucans, mannans, chitin and chitosan. It also contains proteins and lipids, which are often associated with these polysaccharides [25]. The knowledge of the participation of C. albicans products in the pathogenesis of infections has substantially expanded, but it is still incomplete in many aspects. Nevertheless, it is known that their multilayer, hard permeable cell wall is a strong barrier to the operation of antifungal drugs. Thus, it seems advisable to search for products which could weaken their structure. Essential oils, even if used at low concentrations have the desired characteristic, which has been proved in our study. It is generally assumed that the mechanisms by which the constituents of essential oils inhibit the growth of microorganisms may be partially dependent on their hydrophobicity. It enables them to embed in the cell wall, damage the lipid layer of the cell membrane and mitochondria, impair enzyme systems and exhibit side effects on various proteins $[4,5,13,14]$. Some of them inhibit microbial growth by causing also a global arrest in protein synthesis or inducing cytoplasm coagulation [13]. Our results have shown that essential oils cause changes in the composition of the cell wall of Candida, since its sensitivity to Calcofluor White, Congo Red, or SDS definitely have increased. It has been reported that Calcofluor binds to $\beta$-linked fibrillar polymers, interferes with chitin assembly resulting in growth rate reduction, and alteres incorporation of mannoproteins into cell wall. Growth inhibition by detergent SDS was connected with an increases in wall porosity, solubilization of the plasma membrane, whereas Congo Red altered glucan synthesis and assembly $[4,25,26]$. However, by weakening the cell wall by essential oil action, effects of the above cell-wall disrupting agents increased, rendering the cell more susceptible to their lower concentrations, which we have shown in our report (Figure 2).

Another question which we asked was if an efficient oxidative stress response of Candida will be affected by essential oils action. The response may be of clinical interest, since it is important for $C$. albicans invasion and colonization of host tissues and survival within the host cells (phagocytes) in the course of an in vivo infection. $C$. albicans strains show in vitro a great natural resistance to 
$\mathrm{H}_{2} \mathrm{O}_{2}(10-50 \mathrm{mM})$. It has been reported that various $\mathrm{H}_{2} \mathrm{O}_{2}$ treatments have distinct effects on antioxidant enzymes (catalase, superoxide dismutase, glutathione oxidase) [27-29]. Therefore, our observation that preincubation of C. albicans with essential oils (either short with MIC or longer with $1 / 2 \mathrm{MIC}$ ) decreased tolerance to oxidative stress induced by all concentrations of $\mathrm{H}_{2} \mathrm{O}_{2}$ used $(12.5,25.0,50.0 \mathrm{mM})$ suggests, that the activity of various anti-oxidative enzymes could be decreased. It cannot be ruled out that the architecture of the cell wall proteome might be changed by possibly preventing correct positioning and anchoring of cell wall localized superoxide dismutase or other proteins that are directly or indirectly responsible for countering oxidative stress damage [14,20,27-29]. Our results indicate that some essential oils with antifungal activity, such as Lemon balm, can be considered in the future for more clinical evaluations and possible applications, other than the one currently used. For example, they could be introduced into modern palliative care in patients with cancer fungating wounds or diabetic foot [22,30-33].

\section{Acknowledgements}

The work was supported by the National Research Center, Poland, Grant No. 2011/01/N/NZ6/00317, and by University of Lodz (2012) for A.B. The authors wish to thank M. Więckowska-Szakiel for technical assistance.

\section{REFERENCES}

[1] S. A. Messer, R. N. Jones and T. R. Fritsche, "International Surveillance of Candida spp. and Aspergillus spp. Report from the SENTRY Antimicrobial Surveillance Program," Journal of Clinical Microbiology, Vol. 44, No. 5, 2006, 2003, pp. 1782-1787. doi:10.1128/JCM.44.5.1782-1787.2006

[2] E. Mlinarić-Missoni, S. Kalenić, M. Vukelić, D. De Syo, M. Belicza and V. Vazić-Babić, "Candida Infections of Diabetic Foot Ulcers," Diabetologia Croatica, Vol. 34, No 1, 2005, pp. 29-35.

[3] R. Rajeshkumar and M. Sundararaman, "Emergence of Candida spp. and Exploration of Natural Bioactive Molecules for AntiCandidal Therapy-Status Quo," Mycoses, Vol. 55, No. 3, 2012, pp. e60-e73. doi:10.1111/j.1439-0507.2011.02156.x

[4] F. Silva, S. Ferreira, A. Duarte, D. I. Mendonca and F. C. Domingues, "Antifungal Activity of Coriandrum sativum Essential Oil, Its Mode of Action against Candida Species and Potential Synergism with Amphotericin B," Phytomedicine, Vol. 19, No. 1, 2011, pp. 42-47. doi:10.1016/i.phymed.2011.06.033

[5] F. Solórzano-Santos and M. G. Miranda-Novales, "Essential Oils from Aromatic Herbs as Antimicrobial Agents," Current Opinion in Biotechnology, Vol. 23, No. 2, 2012, pp. 136-141. doi:10.1016/j.copbio.2011.08.005

[6] Mikolajewska, S. Schwartz and M. Ruhnke, "Antifungal
Treatment Strategies in Patients with Haematological Diseases and Cancer: From Prophylaxis to Empirical, Pre-Emptive and Targeted Therapy," Mycoses, Vol. 55, No. 1, 2012, pp. 2-16. doi:10.1111/j.1439-0507.2010.01961.x

[7] P. Pozzatti, E. S. Loreto, P. G. M. Lopes, M. L. Athayde, J. M. Santurio and S. H. Alves, "Comparison of the Susceptibilities of Clinical Isolates of Candida albicans and Candida dubliniensis to Essential Oils," Mycoses, Vol. 53, No. 1, 2010, pp. 12-15. doi:10.1111/j.1439-0507.2008.01643.x

[8] J. Reichling, P. Schnitzler, U. Suschke and R. Saller, "Essential Oils of Aromatic Plants with Antibacterial, Antifungal, Antiviral, and Cytotoxic Properties - An Overview," Forschende Komplementarmedizin, Vol. 16, No. 2, 2009, pp. 79-90. doi:10.1159/000207196

[9] A. Rosato, C. Vitali, D. Gallo, L. Balenzano, R. Mallamaci, "The Inhibition of Candida Species by Selected Essential Oils and Their Synergism with Amphotericin B," Phytomedicine, Vol. 15, No. 8, 2008, pp. 635-638. doi:10.1016/j.phymed.2008.05.001

[10] A. Budzyńska, M. Więckowska-Szakiel, D. Kalemba, B. Sadowska and B. Różalska, "The Optimization of Methods Utilized for Testing the Antibacterial Activity of Essential Oils," Medycyna Doświadczalna i Mikrobiologia, Vol. 61, No. 3, 2009, pp. 281-287 (in polish).

[11] A. Budzyńska, M. Więckowska-Szakiel, B. Sadowska, D. Kalemba and B. Różalska, "Antibiofilm Activity of Selected Plant Essential Oils and Their Major Components," Polish Journal of Microbiology, Vol. 60, No. 1, 2011, pp. 35-41.

[12] M. J. Abad, M. Ansuategui and P. Bermejo, "Active Antifungal Substances from Natural Sources," Arkivoc: Archive for Organic Chemistry, Vol. vii, No. 7, 2007, pp. 116-145.

[13] F. Bakkali, S. Averbeck, D. Averbeck and M. Idaomarb, "Biological Effects of Essential Oils-A Review," Food and Chemical Toxicology, Vol. 46, No. 2, 2008, pp. 446475. doi:10.1016/j.fct.2007.09.106

[14] A. N. Devkatte, G. B. Zore and S. M. Karuppayil, "Potential of Plant Oils as Inhibitors of Candida albicans Growth," FEMS Yeast Research, Vol. 5, No. 9, 2005, pp. 867-873. doi:10.1016/j.femsyr.2005.02.003

[15] R. Khosravi, H. Shokri, S. Kermani, M. Dakhili, M. Madani and S. Parsa, "Antifungal Properties of Artemisia sieberi and Origanum vulgare Essential Oils against Candida glabrata Isolates Obtained from Patients with Vulvovaginal Candidiasis," Journal of Medical Mycology, Vol. 21, No. 2, 2011, pp. 93-99. doi:10.1016/j.mycmed.2011.01.006

[16] K. Credito, K. Kosowska-Shick and P. C. Appelbaum, "Mutant Prevention Concentration (MPC) of Four Carbapenems against Gram-Negative Rods," Antimicrobial Agents and Chemotherapy, Vol. 54, No. 6, 2010, pp. 2692-2695. doi:10.1128/AAC.00033-10

[17] K. Drlica and M. Malik, "Fluoroquinolones: Action and Resistance," Current Topics in Medicinal Chemistry, Vol. 3, No. 3, 2002, pp. 249-282. 


\section{doi: $10.2174 / 1568026033452537$}

[18] M. E. Klepser, E. J. Ernst, R. E. Lewis, M. E. Ernst and M. A. Pfaller, "Influence of Test Conditions on Antifungal Time-Kill Curve Results: Proposal for Standardized Methods," Antimicrobial Agents and Chemotherapy, Vol. 42, No. 5, 1998, pp. 1207-1212.

[19] M. Hăncianu, A. C. Aprotosoaie, E. Gille, A. Poiată, C. Tuchiluş, A. Spac and U. Stănescu, "Chemical Composition and in Vitro Antimicrobial Activity of Essential Oil of Melissa officinalis L. from Romania," Revista medicochirurgicala a Societatti de Medici si Naturalisti din Iasi, Vol. 112, No. 3, 2008, pp. 843-847.

[20] N. Mimica-Dukic, B. Bozin, M. Sokovic and N. Simin, "Antimicrobial and Antioxidant Activities of Melissa officinalis L. (Lamiaceae) Essential Oil," Journal of Agricultural and Food Chemistry, Vol. 52, No. 9, 2004, pp. 2485-2489. doi:10.1021/jf030698a

[21] A. K. Tyagi and A. Malik, "Liquid and Vapour-Phase Antifungal Activities of Selected Essential Oils against Candida albicans: Microscopic Observations and Chemical Characterization of Cymbopogon citratus," BMC Complementary and Alternative Medicine, Vol. 10, 2010, p. 65 . doi: $10.1155 / 2012 / 692625$

[22] A. E. Edris, "Pharmaceutical and Therapeutic Potentials of Essential Oils and their Individual Volatile Constituents: A Review," Phytotherapy Research, Vol. 21, No. 4, 2007, pp. 308-323. doi:10.1002/ptr.2072

[23] D. Kalemba and A. Kunicka, "Antibacterial and Antifungal Properties of Essential Oils," Current Medicinal Chemistry, Vol. 10, No. 10, 2003, pp. 813-829. doi:10.2174/0929867033457719

[24] J. Kim, M.R Marschal, C. Wei, "Antibacterial Activity of Some Essential Oil Components against Five Foodborne Pathogens," Journal of Agricultural Chemistry, Vol. 43, No. 11, 1995, pp. 2839-2845. doi:10.1021/jf00059a013

[25] R. Hashash, S. Younes, W. Bahnan, J. El Koussa, K. Maalouf, H. I. Dimassi and R. A. Khalaf, "Characterisation of Pga1, a Putative Candida albicans Cell Wall Protein Necessary for Proper Adhesion and Biofilm Formation," Mycoses, Vol. 54, No. 6, 2011, pp. 491-500. doi:10.1111/j.1439-0507.2010.01883.x
[26] R. K. Shields, M. H. Nguyen, E. Press and C. J. Clancy, "Five-Minute Exposure to Caspofungin Results in Prolonged Post-Antifungal Effects and Eliminates the Paradoxical Growth of Candida albicans," Antimicrobial Agents and Chemotherapy, Vol. 55, No.7, 2011, pp. 3598-3602. doi:10.1128/AAC.00095-11

[27] T. Missall, J. K. Lodge and J. E. McEwen, "Mechanisms of Resistance to Oxidative and Nitrosative Stress. Implications for Fungal Survival in Mammalian Hosts," Eukaryotic Cell, Vol. 3, No. 4, 2004, pp. 835-846. doi:10.1128/EC.3.4.835-846.2004

[28] A. Bink, D. Vandenbosch, T. Coenye, H. Nelis, B. P. A. Cammue and K. Thevissen, "Superoxide Dismutases Are Involved in Candida albicans Biofilm Persistence against Miconazole," Antimicrobial Agents and Chemotherapy, Vol. 55, No. 9, 2011, pp. 4033-4037. doi:10.1128/AAC.00280-11

[29] A. Enjalbert, D. M. MacCallum, F. C. Odds and A. J. P. Brown, "Niche-Specific Activation of the Oxidative Stress Response by the Pathogenic Fungus Candida albicans," Infection and Immunity, Vol. 75, No. 5, 2007, pp. 2143-2151. doi:10.1128/IAI.01680-06

[30] P. H. Warnke, E. Sherry, P. A. J. Russo, Y. Acil, J. Wiltfang, S. Sivananthan, J. C. Roldàn, S. Schubert, J. P. Bredee and I. N. Springer, "Antibacterial Essential Oils in Malodorous Cancer Patients: Clinical Observations in 30 Patients," Phytomedicine, Vol. 13, No. 7, 2006, pp. 463467. doi:10.1016/j.phymed.2005.09.012

[31] S. Hampton, "Malodorous Fungating Wounds: How Dressings Alleviate Symptoms," British Journal of Community Nursing, Vol. 13, No. 6, 2008, pp. S34-S36.

[32] D. Mercier and A. Knevitt, "Using Topical Aromatherapy for the Management of Fungating Wounds in a Palliative Care Unit," Journal of Wound Care, Vol. 14, No. 10, 2005, pp. 497-498.

[33] E. Sherry, H. Boeck and P. H. Warnke, "Topical Application of a New Formulation of Eucalyptus Oil Phytochemical Clears Methicillin-Resistant Staphylococcus aureus Infection," American Journal of Infection Control, Vol. 29, No. 5, 2001, pp. 346. doi:10.1067/mic. 2001.117403 